\title{
Lipid-containing osmoprotective eye drops in contact lens wearers
}

This article was published in the following Dove Press journal:

Clinical Ophthalmology

10 October 2014

Number of times this article has been viewed

\section{Seray Aslan Bayhan \\ Hasan Ali Bayhan}

Ophthalmology Department, Bozok University Faculty of Medicine, Yozgat, Turkey
Correspondence: Seray Aslan Bayhan Ophthalmology Department, Bozok University Faculty of Medicine, Adnan Menderes Bulvarı, Yozgat, 66200 Turkey Tel +90 5052729225

Email seraybayhan@hotmail.com

\section{Dear editor}

We would like to congratulate Kaercher et $\mathrm{al}^{1}$ on their prospective study of Optive Plus (Allergan, Inc., Irvine, CA, USA) in the treatment of patients with dry eye. In this study the authors reported that Optive Plus effectively reduced the signs and symptoms of patients with all types of dry eye and they recommended the use of this artificial tear especially in lipid-deficient dry eye. We think that some important issues need more thorough discussion.

It is known that contact lenses (CLs) are becoming increasingly popular and a lot of people have begun to use CLs as an optical correction every day. Unfortunately, it was found that up to $50.1 \%$ of CL wearers report a sensation of dryness. ${ }^{2}$ The presence of a CL has been shown to adversely affect the tear film characteristics, increase tear evaporation, and reduce the ability to produce adequate tears with concurrent increase in tear osmolarity. It has been suggested that increased tear osmolarity may accompany CL-related dry eye and even the most contemporary CL types (ie, silicone hydrogel lenses) can elevate the tear osmolarity. ${ }^{3}$

The recent report from the Contact Lens Discomfort Workshop reported that tear film changes in $\mathrm{CL}$ wearers are responsible for $\mathrm{CL}$ discomfort. ${ }^{4}$ Hyperosmolarity may be the trigger for an inflammatory cascade resulting in the production of inflammatory cytokines which can lead to increased apoptosis of corneal and conjunctival epithelial cells and conjunctival goblet cells. ${ }^{5}$ Lubricant eye drops that are able to restore the physiological osmolarity of the tear film could reduce the effects of hyperosmotic distress to cells, thus providing osmoprotection. Thus, we think that usage of osmoprotective eye drops can be reasonable in CL wearers. We are also conducting research in dry eye among CL users and we observed that instillation of osmoprotective eye drops (Optive) prevents the increment of tear osmolarity in patients wearing CLs, and Optive has the potential to improve ocular comfort more than the commercially available lubricant solutions. Optive eye drops contain erythritol and L-carnitine osmolytes that have been shown to provide osmoprotection. ${ }^{6}$ Optive Plus contains the ingredients of Optive in addition to a lipid component, castor oil.

The authors ${ }^{1}$ mentioned in the study that Optive Plus is particularly effective in lipiddeficient dry eye patients. From the design of Kaercher et al's study, ${ }^{1}$ we understood that $\mathrm{CL}$ usage is not an exclusion criterion. As we know that $\mathrm{CL}$ wearing, a common cause of lipid-deficient dry eye, is associated with increased tear evaporation, ${ }^{3}$ it is expected that lipid-containing osmoprotective artificial tears (eg, Optive Plus) might be more beneficial than other artificial tears for CL related dry eye by replenishing the lipid-depleted tear film and with their osmoprotective effect. However, in clinical 
practice lipid containing eye drops can induce blurring of vision especially in CL wearers. Thus, we wonder whether the authors should also recommend Optive Plus in patients using CLs and include these patients' results in their study or whether this particular subgroup of patients is not very appropriate for this therapy due to side effects including blurry vision and was thus excluded from the study.

\section{Disclosure}

The authors have no conflicts of interest to disclose.

\section{References}

1. Kaercher T, Thelen U, Brief G, Morgan-Warren R, Leaback R. A prospective, multicenter, noninterventional study of Optive Plus ${ }^{\circledR}$ in treatment of patients with dry eye: the prolipid study. Clin Ophthalmol. 2014;8:1147-1155
2. Guillon M, Maissa C. Dry eye symptomatology of soft contact lens wearers and nonwearers. Optom Vis Sci. 2005;82(9):829-834.

3. Guillon M, Maissa C. Contact lens wear affects tear film evaporation. Eye Contact Lens. 2008;34(6):326-330.

4. Nichols JJ, Willcox MD, Bron AJ, et al. The TFOS International Workshop on contact lens discomfort: executive summary. Invest Ophthalmol Vis Sci. 2013;54(11):TFOS7-TFOS13.

5. Li DQ, Chen Z, Song XJ, Luo L, Pflugfelder SC. Stimulation of matrix metalloproteinases by hyperosmolarity via a JNK pathway in human corneal epithelial cells. Invest Ophthalmol Vis Sci. 2004; 45(12):4302-4311.

6. Baudouin C, Cochener B, Pisella PJ, et al. Randomized, phase III study comparing osmoprotective carboxymethylcellulose with sodium hyaluronate in dry eye disease. Eur J Ophthalmol. 2012; 22(5):751-761. 


\section{Authors' reply}

Thomas Kaercher'

Ulrich Thelen ${ }^{2}$

Gerrett Brief ${ }^{3}$

Robert J Morgan-Warren ${ }^{4}$

Richard Leaback ${ }^{4}$

'Augenarztpraxis, Heidelberg, Germany; ${ }^{2}$ University of Münster, Münster, Germany; ${ }^{3}$ Ruhr University, Bochum, Germany;

${ }^{4}$ Allergan Holdings Ltd., Marlow, UK

Correspondence: Thomas Kaercher

Augenarztpraxis, Dossenheimer Landstr 48, D 69121 Heidelberg,

Germany

Tel +496221400888

Fax +49 6221 41 2203

Email thomas.kaercher@meibomius.de

\section{Dear editor}

We are most grateful to Drs S Aslan Bayhan and HA Bayhan for their valuable commentary on our prospective study of Optive Plus ${ }^{\circledR}$ (Allergan, Irvine, CA, USA) and for highlighting the important issue of ocular dryness experienced by contact lens wearers. ${ }^{1}$

We agree that it may be appropriate for contact lens wearers to use osmoprotective eye drops. Our study was an observational, non-interventional examination of how Optive Plus $^{\circledR}$ performs in routine clinical practice. Consequently, it was not appropriate to exclude contact lens wearers $-10.7 \%$ of the patient population indicated that they wore contact lenses. The primary endpoint of our study related to efficacy in the different forms of dry eye disease (DED) (aqueousdeficient, lipid-deficient or mixed deficiency). Currently, the data have not been analyzed with regard to the effects of Optive Plus ${ }^{\circledR}$ in contact lens wearers, specifically.

We agree with Drs S Aslan Bayhan and HA Bayhan that an artificial tear for contact lens-related DED should replenish the lipid-depleted tear film and offer osmoprotection. ${ }^{2}$ Optive Plus ${ }^{\circledR}$ contains the osmolytes erythritol, L-carnitine, and glycerol (in addition to carboxymethylcellulose and castor oil) and therefore has the potential to fulfil this role.,
Drs S Aslan Bayhan and HA Bayhan have noted that the lipid components of artificial tears can cause blurred vision, which may be particularly disturbing in contact lens wearers. Early formulations of lipid-containing eye drops caused blurred vision, ${ }^{5}$ but this problem now seems to have been resolved. ${ }^{6,7}$ Indeed, homogenized eye drops containing a low-concentration of castor oil relieved the symptoms of dry eye without causing blurred vision in patients with meibomian gland dysfunction. ${ }^{7}$ In this study, although a minority of patients were contact lens wearers, only $1.7 \%$ $(20 / 1,209)$ of patients reported blurred vision with Optive Plus ${ }^{\circledR}{ }^{4}$ Therefore, Optive Plus ${ }^{\circledR}$ may be a suitable option for the treatment of DED in contact lens wearers.

Once again, we would like to extend our thanks to Drs S Aslan Bayhan and HA Bayhan for their comments on our Optive Plus ${ }^{\circledR}$ study and we look forward to seeing the results of their research on Optive ${ }^{\circledR}$ in contact lens-wearing DED patients.

\section{Disclosure}

The authors have no conflicts of interest to disclose.

\section{References}

1. Guillon M, Maissa C. Dry eye symptomatology of soft contact lens wearers and nonwearers. Optom Vis Sci. 2005;82(9):829-834.

2. Rohit A, Willcox M, Stapleton F. Tear lipid layer and contact lens comfort: a review. Eye Contact Lens. 2013;39(3):247-253.

3. Baudouin C, Cochener B, Pisella PJ, et al. Randomized, phase III study comparing osmoprotective carboxymethylcellulose with sodium hyaluronate in dry eye disease. Eur J Ophthalmol. 2012; 22(5):751-761.

4. Kaercher T, Thelen U, Brief G, Morgan-Warren RJ, Leaback R. A prospective, multicentre, non-interventional study of Optive Plus ${ }^{\circledR}$ in the treatment of patients with dry eye: The prolipid study. Clin Ophthalmol. 2014;8:1147-1155.

5. Geerling G, Tauber J, Baudouin C, et al. The international workshop on meibomian gland dysfunction: report of the subcommittee on management and treatment of meibomian gland dysfunction. Invest Ophthalmol Vis Sci. 2011;52(4):2050-2064.

6. Benelli U. Systane lubricant eye drops in the management of ocular dryness. Clin Ophthalmol. 2011;5:783-790.

7. Goto E, Shimazaki J, Monden Y, et al. Low-concentration homogenized castor oil eye drops for noninflamed obstructive meibomian gland dysfunction. Ophthalmology. 2002;109(11):2030-2035.
Clinical Ophthalmology

\section{Publish your work in this journal}

Clinical Ophthalmology is an international, peer-reviewed journal covering all subspecialties within ophthalmology. Key topics include: Optometry; Visual science; Pharmacology and drug therapy in eye diseases; Basic Sciences; Primary and Secondary eye care; Patient Safety and Quality of Care Improvements. This journal is indexed on

\section{Dovepress}

PubMed Central and CAS, and is the official journal of The Society of Clinical Ophthalmology (SCO). The manuscript management system is completely online and includes a very quick and fair peer-review system, which is all easy to use. Visit http://www.dovepress.com/ testimonials.php to read real quotes from published authors. 